\title{
Dietary intake and nutritional status of US adult marijuana users: results from the Third National Health and Nutrition Examination Survey
}

\author{
Ellen Smit* and Carlos J Crespo \\ Department of Social and Preventive Medicine, School of Medicine, University at Buffalo, SUNY, Buffalo, NY \\ 14214, USA
}

\begin{abstract}
Objectives: This study examined dietary intakes and nutritional status of marijuana users and non-current marijuana users in US adults aged 20 to 59 years.

Methods: We used data from the Third National Health and Nutrition Examination Survey (NHANES III), 1988-1994. Information on self-reported drug use, including marijuana, was obtained as part of the NHANES III physical examination component. Nutritional status was assessed using height and weight, and blood biochemistries. Dietary intake was assessed using a 24-hour recall and a food-frequency questionnaire.

Results: Among adults 20-59 years of age, 45\% reported ever having used marijuana in their lifetime. A total of $8.7 \%$ reported using marijuana in the past month. Current marijuana users had higher intakes of energy and nutrients than non-current marijuana users; however, body mass index (BMI) was slightly lower. We found higher cigarette-smoking rates and higher consumption of sodas and alcohol, specifically beer, among marijuana users than among non-current marijuana users. Marijuana users also consumed more sodium, fewer fruits, and more pork, cheese, and salty snacks. Nutritional status, using indicators of serum nutrients, serum albumin, haematocrit and haemoglobin, was similar between marijuana users and non-current marijuana users. Serum carotenoid levels were lower among marijuana users, independent of cigarette smoking.

Conclusion: Dietary intake was different among marijuana users than among noncurrent marijuana users. Although overall nutritional status was similar, serum carotenoid levels were lower in marijuana users. The long-term health effects of these differences in marijuana users deserve careful consideration in future research.
\end{abstract}

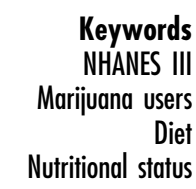

Marijuana is the most commonly used illicit drug in the USA. Approximately one-third of the US population aged 12 years or older, or 72 million persons, have reported smoking marijuana at some point in their life ${ }^{1}$. Trends in marijuana use have not changed dramatically since $1991^{1}$. The National College Health Risk Behavior Survey found that $59.6 \%$ of students aged 25 years and older reported ever having used marijuana, with $8.3 \%$ reporting being current users of marijuana ${ }^{2}$.

In response to public pressure to allow for the medical use of marijuana, the Office of National Drug Control Policy of the United States evaluated the scientific evidence for the benefits and risks of using marijuana as a medicine ${ }^{3}$. We know little about the long-term effects of marijuana use on the human body and other concomitant health behaviours associated with marijuana consumption.
The report called for an increase in research to evaluate the health consequences of marijuana use and other behaviours associated with consumption of marijuana. It is important that we learn more about the changes in dietary habits that accompany marijuana use and their beneficial or detrimental effect in the development of chronic diseases later in life.

Use of psychoactive drugs, including marijuana, has been reported to affect food and beverage consumption, and body weight ${ }^{4-8}$. Mendelson studied chronic marijuana users in a laboratory setting and found that the participants increased caloric intake and gained weight during periods of active marijuana use $\mathrm{e}^{5}$. Similarly, after administering marijuana to 12 healthy volunteers, Hollister found total food intake, and reports of hunger and appetite, to increase ${ }^{6}$. Foltin et al. also showed that 
marijuana users increased their caloric intake and that this increase was mostly due to increases in between-meal snack items ${ }^{7}$. In a random double-blind study of eight subjects, Zwillich et al. showed that the metabolic rate was increased 15 to $120 \mathrm{~min}$ after marijuana administration $^{8}$.

Most of these studies have focused on the immediate effect of marijuana use. Limited information is available about the intake of marijuana users in the free-living population. We examined dietary intake and related factors in the non-institutionalised US adult population among those reporting using marijuana and those not currently using marijuana.

\section{Methods}

\section{Study population}

The study population consists of participants of the Third National Health and Nutrition Examination Survey, 19881994 (NHANES III). The study design is described in detail in the Plan and Operation of the Third National Health and Nutrition Examination Survey? ${ }^{9}$ NHANES III uses a highly stratified multistage probability design and employs over-sampling of the elderly, non-Hispanic blacks and Mexican-Americans.

We limit this analysis to adults defined as aged 20 and above. Additionally, only participants up to age 60 years were asked about marijuana use. Our analytic sample thus consists of those participants aged 20-59 years. A sample of 14,883 persons 20-59 years old was selected and asked to complete an extensive in-home interview and a health examination at the mobile examination centre (MEC). A total of 12,229 (82\% of the sample persons) were interviewed, and 11,271 (76\% of the sample persons) were examined. The total analytic sample, excluding incomplete and unreliable dietary recalls and incomplete marijuana data, is 10,623 adults, which is $94 \%$ of those participants who were examined and $71 \%$ of the total persons sampled.

The household interview generally took place one to three weeks prior to the MEC health examination. Data on marijuana use were collected during the health examination. Non-current marijuana users included never users ( $n=5843)$ and those who reported ever having used marijuana, but who had not used marijuana in the past month $(n=3928)$. Initial analysis showed these two groups to be similar in social characteristics (e.g. age and education) and dietary intake, and therefore they were combined $(n=9771)$. We classified participants who reported using marijuana in the past month (number of days in the past month) by frequency of use: less than or equal to four days per month $(n=541)$, five to 10 days per month $(n=135)$, and 11 or more days per month $(n=176)$. For the purpose of this paper, we shall refer to these groups as light, moderate and heavy users, respectively.

\section{Dietary intake assessment}

One 24-hour dietary recall was collected during the visit to the MEC. The dietary interviewers used the Dietary Data Collection system, which is an automated, standardised, interactive dietary interview and coding system. The system was specifically developed for NHANES III by the University of Minnesota Nutrition Coordinating Center. Participants were asked to report all foods and beverages consumed, excluding plain drinking water, during the previous 24 hours, from midnight to midnight.

During the household interview, a food-frequency questionnaire (FFQ) with a one month reference period was administered by an interviewer. The FFQ did not include information on serving size and is not designed to provide quantitative nutrient data. It does provide information on the frequency of consumption of specific foods or food groupings, such as frequency of beer use or frequency of the use of salty snacks during the past month.

\section{Blood measurements}

Blood concentrations were determined on a specimen obtained by venipuncture during the visit to the MEC. Details of the laboratory procedures can be found in the Laboratory Procedures Used in NHANES III ${ }^{10}$. The Coulter Counter Model S-PLUS JR with Coulter histogram differential is a quantitative, automated haematology analyser and was used to determine 16 haematologic parameters including haemoglobin and haematocrit. Albumin was measured with the Boehringer Manneheim Diagnostics (BMD, Indianapolis, IN) albumin system and the bromocresol purple binding agent. Folate was measured by using the Bio-Rad Laboratories 'Quantaphase Folate' radioassay kit. Serum levels of vitamin A (retinol), vitamin $\mathrm{E}$ (tocopherol) and carotenoids were measured by isocratic high-performance liquid chromatography with detection at three different wavelengths.

Serum total cholesterol was analysed enzymatically in the Johns Hopkins University Lipid Research Clinic Laboratory, using the method of Allain et al. ${ }^{11}$ and the reagent mixture from BMD (Cholesterol/HP, catalogue no. 816302).

\section{Statistical analysis}

Total and adjusted means and variances of dietary intake and blood biochemistries were calculated using SAS (Release 6.12, 1996; SAS, Inc., Cary, NC) and SUDAAN (Release 7.5.2, 1998; Research Triangle Institute, NC). Sample weights, provided by the National Center for Health Statistics, were used to correct for differential selection probabilities and to adjust for non-coverage and non-response. Adjustments for confounding variables were done using weighted general linear multivariate regressions and we report the least of square means. Significant differences between non-current marijuana users and marijuana users were determined by two-sided $t$-tests, and $P$-values are reported at levels $\leq 0.05$ and $\leq 0.0001$. 
Table 1 Social characteristics of US adults, 20-59 years of age, according to marijuana use in the past month

\begin{tabular}{|c|c|c|c|c|}
\hline & $\begin{array}{l}\text { Non-current users } \\
\quad(n=9771)\end{array}$ & $\begin{array}{c}1-4 \text { month }^{-1} \\
(n=541)\end{array}$ & $\begin{array}{c}5-10 \text { month }^{-1} \\
(n=135)\end{array}$ & $\begin{array}{c}11+\text { month }^{-1} \\
(n=176)\end{array}$ \\
\hline Age (years $\pm S E$ ) & $38 \pm 0.2$ & $31 \pm 0.5$ & $31 \pm 0.8$ & $32 \pm 0.9$ \\
\hline \multicolumn{5}{|l|}{ Race $(\%)$} \\
\hline White & 75 & 73 & 75 & 74 \\
\hline Black & 11 & 17 & 17 & 13 \\
\hline Mexican-American & 6 & 4 & 5 & 4 \\
\hline Married (\%) & 69 & 47 & 51 & 61 \\
\hline \multicolumn{5}{|l|}{ Gender $(\%)$} \\
\hline Male & 47 & 64 & 65 & 77 \\
\hline Female & 53 & 36 & 35 & 23 \\
\hline \multicolumn{5}{|l|}{ Income (\%) } \\
\hline$<\$ 20,000$ & 26 & 41 & 52 & 43 \\
\hline$\$ 20,000-49,999$ & 46 & 39 & 38 & 49 \\
\hline$\$ 50,000+$ & 28 & 20 & 11 & 8 \\
\hline Poverty income ratio $<1.0(\%)$ & 12 & 23 & 12 & 13 \\
\hline \multicolumn{5}{|l|}{ Education (\%) } \\
\hline Less than high school & 19 & 22 & 16 & 32 \\
\hline High school & 34 & 42 & 47 & 35 \\
\hline More than high school & 47 & 35 & 37 & 33 \\
\hline Smokers (\%) & 29 & 60 & 67 & 70 \\
\hline Number of cigarettes in the past 5 days (mean \pm SE) & $26.8 \pm 1.4$ & $50.0 \pm 3.9$ & $52.4 \pm 8.8$ & $73.2 \pm 8.2$ \\
\hline Body mass index (mean $\pm \mathrm{SE})$ & $26.6 \pm 0.1$ & $25.0 \pm 0.4$ & $26.1 \pm 0.6$ & $24.7 \pm 0.3$ \\
\hline
\end{tabular}

\section{Results}

Among adults 20-59 years of age, 45\% reported ever having used marijuana, with $8 \%$ using it once or twice, $12 \%$ using three to 10 times, $12 \%$ using 11-99 times, and 13\% using marijuana 100 times or more in their lifetime. A total of $8.7 \%$ of the sample population reported using marijuana in the past month, with $5.5 \%$ using one to four times a month (light users), 1.3\% using five to 10 times a month (moderate users), and $1.9 \%$ using 11 or more times a month (heavy users).

Table 1 shows the social characteristics of adults, 20 to 59 years of age, who participated in NHANES III by marijuana use. Non-current users were older than users and the proportion of men was higher among users than non-current users. The proportion of participants with annual household income of greater than $\$ 50,000$ was highest in the non-current users and lowest in the heavy users. Similarly, the proportion of participants with an education level of more than high school was highest in the non-current users and lowest in the heavy users.

The proportion of participants who reported smoking cigarettes was lowest in the non-current users and highest in the heavy users. Among those who reported smoking cigarettes, the mean number of cigarettes in the past five days was also lowest in the non-current users and highest in the heavy users. As shown in Table 1, mean body mass index (BMI) was lower in the heavy users than in the noncurrent users $(P<0.0001)$ and these differences remained after adjusting for age, gender, education, cigarette smoking and caloric intake $(P=0.003)$ (data not shown). A similar proportion was underweight $(\mathrm{BMI}<18.5)$ among the heavy users $(1.3 \%)$ and all other groups (2.6\% non-users, 2.3\% light users, $1.0 \%$ moderate users). The proportion overweight or obese $(\mathrm{BMI} \geq 25)$ was also similar among all groups: 54\% among non-current users, $42 \%$ among the light users, $49 \%$ among the moderate users, and $42 \%$ among the heavy users.

Dietary intake is shown in Tables 2 and 3. Total caloric intake was highest in the heavy users. Light, moderate and heavy users consumed 24\%, 28\% and 41\%, respectively, more calories than non-current users. After adjusting for age, sex and education, the calories were 13\%, 17\% and $25 \%$, respectively, higher than for the non-current users. The percentage of energy from fat was lower among the heavy users than among the non-current users, whereas the percentage of calories from alcohol was higher in the heavy users than in the non-current users.

Absolute and energy-adjusted values are provided for the grams of protein, carbohydrate, fat and alcohol (Table 2 ), and micronutrients (Table 3). The absolute intake reflects the actual amount consumed and is of interest for examining differences in intake among the users and noncurrent users. The energy-adjusted values are of interest for examining the amount of nutrient relative to the total energy intake. Absolute intakes among heavy users were higher for all macronutrients and alcohol than among the non-current users. Fat and alcohol intake remained higher after energy adjustment.

Women tend to consume fewer calories than men, and more men than women use marijuana. Therefore, we compared dietary intake between male non-current marijuana users and male marijuana users, and found the macronutrient intakes to be higher in users than in non-current users. We also compared women non-current marijuana users and women marijuana users, and again found macronutrient intakes to be higher in users than in 
Table 2 Dietary intake of macronutrients in US adults, 20-59 years of age, according to marijuana use in the past month

\begin{tabular}{|c|c|c|c|c|c|c|c|c|}
\hline & \multicolumn{2}{|c|}{ Non-current users $(n=9771)$} & \multicolumn{2}{|c|}{$1-4$ month $^{-1}(n=541)$} & \multicolumn{2}{|c|}{$5-10$ month $^{-1}(n=135)$} & \multicolumn{2}{|c|}{$11+$ month $^{-1}(n=176)$} \\
\hline & Mean \pm SE & Adjusted† & Mean \pm SE & Adjusted $\dagger$ & Mean \pm SE & Adjusted $\dagger$ & Mean \pm SE & Adjusted $\dagger$ \\
\hline Total calories & $2271 \pm 22$ & 2253 & $2823 \pm 78^{\star \star}$ & $2557^{\star \star}$ & $2917 \pm 130^{\star \star}$ & $2639^{\star \star}$ & $3196 \pm 181^{\star \star}$ & $2835^{\star *}$ \\
\hline Fat $(\%)$ & $34.0 \pm 0.3$ & 34.0 & $33.9 \pm 0.6$ & 33.8 & $30.8 \pm 1.1^{\star}$ & $30.7^{*}$ & $31.6 \pm 0.9^{\star}$ & 31.5 \\
\hline Carbohydrate (\%) & $49.4 \pm 0.3$ & 49.3 & $46.2 \pm 1.2^{*}$ & $46.3^{*}$ & $44.7 \pm 1.9^{*}$ & $44.7^{*}$ & $49.2 \pm 1.2$ & 49.6 \\
\hline Protein (\%) & $15.2 \pm 0.1$ & 15.3 & $14.5 \pm 0.3^{*}$ & 14.9 & $13.7 \pm 0.6^{*}$ & 14.1 & $14.4 \pm 0.7$ & 14.8 \\
\hline Alcohol (\%) & $2.8 \pm 0.1$ & 2.7 & $6.9 \pm 0.9^{\star \star}$ & $6.6^{\star \star}$ & $12.1 \pm 1.9^{\star *}$ & $11.8^{\star \star}$ & $5.9 \pm 1.1^{*}$ & $5.5^{\star}$ \\
\hline Protein $(\mathrm{g})$ & $85 \pm 1.0$ & 85 & $102 \pm 3.8^{\star \star}$ & 84 & $98 \pm 5.7^{*}$ & 77 & $116 \pm 7.5^{\star \star}$ & 85 \\
\hline Carbohydrate (g) & $275 \pm 2.9$ & 272 & $318 \pm 10.5^{\star \star}$ & $254^{*}$ & $318 \pm 17.1^{\star}$ & 243 & $378 \pm 21.0^{* *}$ & 274 \\
\hline Fat $(g)$ & $88 \pm 1.3$ & 87 & $108 \pm 4.0^{\star *}$ & 85 & $101 \pm 7.0$ & $73^{\star}$ & $116 \pm 8.0^{*}$ & $77^{*}$ \\
\hline Alcohol (g) & $10 \pm 0.6$ & 10 & $29 \pm 3.8^{\star \star}$ & $24^{*}$ & $55 \pm 11.1^{*}$ & $49^{*}$ & $30 \pm 6.5^{\star}$ & $22^{*}$ \\
\hline Fibre $(\mathrm{g})$ & $16.6 \pm 0.2$ & 16.5 & $18.3 \pm 1.0$ & 15.9 & $18.3 \pm 1.4$ & 15.3 & $20.9 \pm 1.6^{*}$ & 16.2 \\
\hline
\end{tabular}

† Adjusted for age, sex and education for percentage of energy; adjusted for age, sex, education and energy for grams of protein, fat, carbohydrate and alcohol. * Significantly different from non-current users, $P \leq 0.05$.

** Significantly different from non-current users, $P \leq 0.0001$

non-current users (data not shown). We therefore report the combined, gender-adjusted data.

Vitamins $\mathrm{B}_{12}$ and $\mathrm{B}_{6}$, folate, thiamin, riboflavin, niacin, calcium, phosphorus, iron, zinc, potassium and sodium were higher among the heavy users than among the noncurrent users. Most of these differences were reduced or disappeared after energy adjustment. Energy-adjusted intakes of carotenes and vitamin C were significantly lower among the heavy users than among non-current users.

We subsequently examined the food-frequency data (Table 4). The frequencies do not include serving sizes and although we can determine the frequency of consumption, we cannot compare the serving size. Marijuana users had a higher frequency of beer, liquor, regular sodas, pork, cheese and salted snacks consumption than non-current users, whereas frequency of diet sodas and fruits consumption was lower.

Table 5 shows serum values for various health indicators and serum nutrient levels. Although serum haemoglobin and haematocrit levels were higher in the marijuana users than in the non-current users, the differences were clinically small. Serum albumin, cholesterol and triglycerides were similar between marijuana users and non-current users. Most of the serum carotenoids were lower in the heavy users than in the noncurrent users.

\section{Discussion}

We examined food consumption, nutrient intake and serum nutrients among US adults, aged $20-59$ years, who participated in the NHANES III and who reported using marijuana in the past month compared with those who did not report using marijuana in the past month. Marijuana users were younger, had a lower income, were more likely to be smokers and were less likely to have completed high school than non-current marijuana

Table 3 Dietary intake of micronutrients in US adults, 20-59 years of age, according to marijuana use in the past month

\begin{tabular}{|c|c|c|c|c|c|c|c|c|}
\hline & \multicolumn{2}{|c|}{ Non-current users ( $n=9771)$} & \multicolumn{2}{|c|}{$1-4$ month $^{-1}(n=541)$} & \multicolumn{2}{|c|}{$5-10$ month $^{-1}(n=135)$} & \multicolumn{2}{|c|}{$11+$ month $^{-1}(n=176)$} \\
\hline & Mean \pm SE & Adjusted $†$ & Mean \pm SE & Adjusted $\dagger$ & Mean \pm SE & Adjusted $\dagger$ & Mean \pm SE & Adjusted $\dagger$ \\
\hline$\overline{\text { Vitamin A (IU) }}$ & $6465 \pm 150$ & 6303 & $5987 \pm 387$ & 5640 & $6009 \pm 792$ & 5526 & $6412 \pm 799$ & 5521 \\
\hline Carotenes (RE) & $515.8 \pm 15.2$ & 505.6 & $435.5 \pm 35.7^{\star}$ & 412.4 & $511.8 \pm 83.8$ & $482.5^{\star}$ & $443.2 \pm 72.8$ & $375.1^{*}$ \\
\hline Vitamin E (mg TE) & $9.9 \pm 0.2$ & 9.6 & $11.4 \pm 0.8^{*}$ & 9.3 & $10.1 \pm 0.9$ & 7.7 & $11.4 \pm 0.9$ & 7.9 \\
\hline Vitamin C (mg) & $105 \pm 2.2$ & 103 & $98 \pm 6.8$ & $83^{\star}$ & $119 \pm 17.1$ & 101 & $98 \pm 10.1$ & $72^{*}$ \\
\hline Vitamin $B_{12}(\mathrm{mcg})$ & $5.3 \pm 0.2$ & 5.3 & $6.5 \pm 0.4^{*}$ & 5.4 & $5.5 \pm 0.4$ & $4.2^{*}$ & $9.4 \pm 1.9^{\star}$ & 7.4 \\
\hline Vitamin $B_{6}(\mathrm{mg})$ & $1.9 \pm 0.2$ & 1.9 & $2.4 \pm 0.3^{*}$ & 2.1 & $2.5 \pm 0.2^{*}$ & 2.1 & $2.5 \pm 0.2^{*}$ & 1.9 \\
\hline Folate $(\mathrm{mcg})$ & $279 \pm 3.6$ & 276 & $357 \pm 26.1^{*}$ & 317 & $322 \pm 16.6^{*}$ & 273 & $373 \pm 34.4^{*}$ & 297 \\
\hline Thiamin (mg) & $1.7 \pm 0.02$ & 1.7 & $2.1 \pm 0.1^{*}$ & 1.7 & $1.8 \pm 0.1$ & $1.4^{*}$ & $2.2 \pm 0.1^{*}$ & 1.6 \\
\hline Riboflavin (mg) & $2.0 \pm 0.02$ & 2.0 & $2.5 \pm 0.1^{*}$ & 2.1 & $2.2 \pm 0.1$ & $1.7^{\star}$ & $2.8 \pm 0.2^{*}$ & 2.1 \\
\hline Niacin (mg) & $24.4 \pm 0.3$ & 24.3 & $30.3 \pm 1.4^{* *}$ & 25.7 & $28.5 \pm 1.7^{*}$ & 23.1 & $34.1 \pm 2.3^{\star \star}$ & 26.1 \\
\hline Calcium (mg) & $852 \pm 12.8$ & 831 & $1002 \pm 47^{*}$ & 813 & $907 \pm 55$ & $686^{*}$ & $1171 \pm 127^{\star}$ & 868 \\
\hline Phosphorus (mg) & $1337 \pm 14$ & 1325 & $1601 \pm 56^{\star *}$ & 1315 & $1520 \pm 74^{*}$ & 1188 & $1848 \pm 131^{*}$ & 1362 \\
\hline Iron (mg) & $15.5 \pm 0.2$ & 15.3 & $19.0 \pm 1.0^{*}$ & 16.5 & $15.7 \pm 0.9$ & $12.5^{\star}$ & $20.4 \pm 1.7^{*}$ & 15.8 \\
\hline Zinc (mg) & $12.0 \pm 0.1$ & 12.1 & $15.8 \pm 0.9^{\star \star}$ & 13.6 & $13.3 \pm 1.0$ & 10.7 & $16.1 \pm 1.2^{*}$ & 11.9 \\
\hline Potassium (mg) & $2893 \pm 27$ & 2883 & $3258 \pm 130^{*}$ & 2836 & $3246 \pm 163^{*}$ & 2735 & $3605 \pm 244^{\star}$ & 2800 \\
\hline Sodium (mg) & $3663 \pm 43$ & 3634 & $4440 \pm 159^{\star *}$ & 3600 & $4216 \pm 238^{*}$ & $3234^{*}$ & $5024 \pm 472^{*}$ & 3630 \\
\hline
\end{tabular}

$\dagger$ Adjusted for age, sex, education and energy intake.

* Significantly different from non-current users, $P \leq 0.05$.

** Significantly different from non-current users, $P \leq 0.0001$. 
Table 4 Frequency of consumption of specific foods and beverages in US adults, 20-59 years of age, according to marijuana use in the past month†

\begin{tabular}{|c|c|c|c|c|}
\hline & $\begin{array}{c}\text { Non-current users } \\
\quad(n=9771)\end{array}$ & $\begin{array}{c}1-4 \text { month }^{-1} \\
(n=541)\end{array}$ & $\begin{array}{c}5-10 \text { month }^{-1} \\
(n=135)\end{array}$ & $\begin{array}{c}11+\text { month }^{-1} \\
(n=176)\end{array}$ \\
\hline Beer & $5.2 \pm 0.2$ & $8.5 \pm 0.8^{*}$ & $18.2 \pm 3.1^{*}$ & $15.7 \pm 6.5$ \\
\hline Wine & $1.5 \pm 0.1$ & $1.9 \pm 0.3$ & $2.7 \pm 0.6^{\star \star}$ & $2.3 \pm 0.5$ \\
\hline Liquor & $1.6 \pm 0.1$ & $2.7 \pm 0.4^{\star *}$ & $3.8 \pm 0.7^{\star *}$ & $2.9 \pm 1.0$ \\
\hline Regular soda & $17.5 \pm 0.5$ & $19.6 \pm 3.1$ & $17.6 \pm 3.5$ & $35.0 \pm 7.8^{* \star}$ \\
\hline Diet soda & $13.1 \pm 0.4$ & $9.7 \pm 1.3^{\star \star}$ & $9.0 \pm 2.1$ & $7.2 \pm 1.5^{\star \star}$ \\
\hline Kool-aid, Hi-C, Hawaiian punch, Tango & $6.1 \pm 0.3$ & $7.2 \pm 129$ & $5.5 \pm 1.0$ & $8.0 \pm 1.5$ \\
\hline Fruits, excluding juice & $24.7 \pm 0.4$ & $19.6 \pm 1.2^{\star \star}$ & $19.9 \pm 2.2^{\star \star}$ & $20.8 \pm 2.6$ \\
\hline Fruit juices & $19.3 \pm 0.4$ & $15.9 \pm 1.1^{\star *}$ & $18.9 \pm 3.4$ & $17.4 \pm 1.9$ \\
\hline Vegetables & $72.1 \pm 0.9$ & $68.8 \pm 2.1$ & $71.1 \pm 3.3$ & $71.5 \pm 3.1$ \\
\hline Pork and ham & $4.0 \pm 0.1$ & $4.6 \pm 0.3^{\star \star}$ & $5.5 \pm 0.8^{\star *}$ & $5.8 \pm 0.7^{\star *}$ \\
\hline Beef & $11.6 \pm 0.2$ & $12.8 \pm 0.7$ & $12.5 \pm 1.7$ & $14.0 \pm 1.6$ \\
\hline Bacon, sausage, luncheon meats & $7.7 \pm 0.2$ & $8.5 \pm 0.6$ & $9.1 \pm 1.1$ & $9.6 \pm 1.3$ \\
\hline Cheese, all types & $12.7 \pm 0.3$ & $14.8 \pm 0.9^{\star *}$ & $17.4 \pm 1.9^{\star *}$ & $15.7 \pm 1.6$ \\
\hline Salted snacks, chips, popcorn, pretzels & $9.0 \pm 0.2$ & $9.1 \pm 0.7$ & $10.9 \pm 1.2$ & $12.6 \pm 1.3^{\star \star}$ \\
\hline
\end{tabular}

† Adjusted for age, sex, education and race-ethnicity.

* Significantly different from non-current users, $P \leq 0.05$.

** Significantly different from non-current users, $P \leq 0.0001$

users. We found caloric intake to be higher among marijuana users than among non-current users and that the intake increased as frequency of marijuana use increased (Table 2). Although energy intake was higher among marijuana users, their BMI was somewhat lower. Additionally, most of the indicators of nutritional status (serum nutrients, serum albumin, haematocrit and haemoglobin) were not different between marijuana users and non-marijuana users.

The higher caloric intake findings agree with other smaller studies looking at the effect of marijuana use on caloric intake ${ }^{5-8}$. Foltin et al. found a $40 \%$ increase in caloric intake among marijuana users ${ }^{7}$, while we found that users had 24 to $40 \%$ higher intakes than non-current users. We also showed that the higher caloric intake came from higher absolute amounts of protein, carbohydrates, fat and alcohol, and more specifically from the higher frequency of beer, liquor, sodas, pork, cheese and salty snacks consumption. It has been suggested that in addition to stimulation of appetite, the reason for higher intakes among marijuana users may be related to the notion that marijuana is often used in social groups where food and alcoholic beverages may be more readily available ${ }^{6}$.

In contrast to some studies that have reported an increase in body weight with marijuana use ${ }^{5}$, we found BMI to be somewhat lower among marijuana users than in non-marijuana users. Given the higher caloric intake, one might expect higher body weights among users than non-current users; however, other factors may affect this relationship. For example, higher energy intake may be an indicator that physical activity and/or metabolic rate could be higher among marijuana users than among noncurrent users. When we adjusted caloric intake for participation in leisure-time physical activity in addition to age, sex and income, we found that the caloric differences remained the same. We also adjusted for

Table 5 Serum nutrient levels and other serum health indicators in US adults, 20-59 years of age, according to marijuana use in the past month

\begin{tabular}{|c|c|c|c|c|c|c|c|c|}
\hline & \multicolumn{2}{|c|}{ Non-current users ( $n=9771)$} & \multicolumn{2}{|c|}{$1-4$ month $^{-1}(n=541)$} & \multicolumn{2}{|c|}{$5-10$ month $^{-1}(n=135)$} & \multicolumn{2}{|c|}{$11+$ month $^{-1}(n=176)$} \\
\hline & Mean $\pm S E$ & Adjusted† & Mean $\pm S E$ & Adjusted $\dagger$ & Mean $\pm S E$ & Adjusted $\dagger$ & Mean \pm SE & Adjusted $\dagger$ \\
\hline Haemoglobin $\left(\mathrm{g} \mathrm{I}^{-1}\right)$ & $142 \pm 0.3$ & 143 & $145 \pm 1.0^{*}$ & $142^{*}$ & $148 \pm 1.8^{*}$ & $145^{\star}$ & $149 \pm 1.8^{*}$ & $143^{*}$ \\
\hline Haematocrit $(\%)$ & $41.9 \pm 0.08$ & 42.1 & $43.0 \pm 0.3^{*}$ & $42.2^{*}$ & $43.4 \pm 0.6^{*}$ & $42.6^{*}$ & $44.0 \pm 0.5^{*}$ & $42.5^{\star}$ \\
\hline Albumin $\left(\mathrm{g} \mathrm{I}^{-1}\right)$ & $42.2 \pm 0.2$ & 42.1 & $42.8 \pm 0.3^{*}$ & 41.9 & $43.2 \pm 0.5^{*}$ & 42.3 & $42.8 \pm 0.3^{*}$ & 41.7 \\
\hline Triglycerides $\left(\mathrm{mmol} \mathrm{I}^{-1}\right)$ & $1.6 \pm 0.03$ & 1.6 & $1.3 \pm 0.08^{*}$ & 1.5 & $1.4 \pm 0.1$ & 1.5 & $1.4 \pm 0.08^{*}$ & 1.4 \\
\hline Cholesterol $\left(\mathrm{mmol} \mathrm{I}^{-1}\right)^{\prime}$ & $5.2 \pm 0.02$ & 5.2 & $4.8 \pm 0.1^{\star *}$ & 5.1 & $5.0 \pm 0.1$ & 5.3 & $4.9 \pm 0.1^{*}$ & 5.1 \\
\hline Folate $\left(\mathrm{nmol} \mathrm{I}{ }^{-1}\right)$ & $14.1 \pm 0.4$ & 13.8 & $12.6 \pm 0.8$ & 14.1 & $13.3 \pm 1.3$ & 14.6 & $14.8 \pm 1.4$ & 16.8 \\
\hline Red-cell folate $\left(\mathrm{nmol} \mathrm{I}^{-1}\right)$ & $427 \pm 6.3$ & 401 & $385 \pm 9.7$ & 392 & $390 \pm 17.1$ & 395 & $393 \pm 22.3$ & 399 \\
\hline Vitamin $A\left(\mu \mathrm{mol} \mathrm{I}^{-1}\right)$ & $2.00 \pm 0.01$ & 2.01 & $2.03 \pm 0.04$ & $2.05^{\star}$ & $2.1 \pm 0.7$ & 2.07 & $2.1 \pm 0.1$ & 2.06 \\
\hline Vitamin $E\left(\mu \mathrm{mol} \mathrm{I}^{-1}\right)$ & $25.6 \pm 0.3$ & 25.9 & $22.6 \pm 0.5^{\star \star}$ & 25.1 & $22.8 \pm 0.7^{*}$ & 25.2 & $22.1 \pm 0.7^{\star \star}$ & 24.6 \\
\hline Beta-carotene $\left(\mu \mathrm{mol} \mathrm{I}^{-1}\right)$ & $0.35 \pm 0.02$ & 0.34 & $0.27 \pm 0.03^{*}$ & 0.32 & $0.23 \pm 0.02^{* *}$ & $0.29^{*}$ & $0.24 \pm 0.03^{*}$ & $0.30^{*}$ \\
\hline Alpha-carotene $\left(\mu \mathrm{mol} \mathrm{I}^{-1}\right)$ & $0.09 \pm 0.02$ & 0.08 & $0.06 \pm 0.01^{*}$ & 0.07 & $0.06 \pm 0.01^{\star *}$ & $0.07^{\star \star}$ & $0.06 \pm 0.01^{\star *}$ & $0.07^{*}$ \\
\hline Lutein/zeaxanthin $\left(\mu \mathrm{mol} \mathrm{I}^{-1}\right)$ & $0.37 \pm 0.01$ & 0.37 & $0.33 \pm 0.01^{\star *}$ & 0.35 & $0.33 \pm 0.02^{\star}$ & 0.36 & $0.30 \pm 0.02^{*}$ & $0.32^{*}$ \\
\hline Lycopene $\left(\mu \mathrm{mol} \mathrm{I}{ }^{-1}\right)$ & $0.46 \pm 0.01$ & 0.45 & $0.47 \pm 0.02$ & 0.44 & $0.50 \pm 0.02$ & 0.46 & $0.43 \pm 0.02$ & 0.40 \\
\hline Beta-cryptoxanthin ( $\mu \mathrm{mol} \mathrm{I}^{-1}$ ) & $0.16 \pm 0.03$ & 0.16 & $0.14 \pm 0.01^{*}$ & $0.14^{*}$ & $0.14 \pm 0.01^{*}$ & $0.14^{*}$ & $0.13 \pm 0.01^{*}$ & 0.14 \\
\hline
\end{tabular}

$\dagger$ Adjusted for age, sex and education.

* Significantly different from non-current users, $P \leq 0.05$.

** Significantly different from non-current users, $P \leq 0.0001$. 
cigarette smoking and again found that the caloric differences remained (data not shown). Zwillich et al. found that the metabolic rate of marijuana users increased for up to $60 \mathrm{~min}$ after marijuana use in a placebocontrolled study of eight volunteers ${ }^{8}$. Although we could not test this hypothesis in our population-based study, a higher metabolic rate may be a plausible explanation that will need to be investigated further.

Some have suggested that drug users have diets poor in vitamins and minerals, which could be a public health concern $^{3,12}$. We found that the majority of absolute vitamin and mineral intakes were higher among marijuana users than among non-current users, and energyadjusted vitamin and mineral intakes were similar between marijuana users and non-current users. Moreover, intakes for most nutrients were within the Recommended Dietary Allowances (RDA) or the Dietary Reference Intakes (DRI). Only folate intake was below the DRI and this was the case for both marijuana users and non-current users.

Serum haemoglobin, haematocrit, albumin and most of the serum nutrients were within normal ranges for both marijuana users and non-current users. This is in agreement with Mendelson, who found no abnormalities in blood chemistries in 70 male chronic marijuana users 5 . We found, however, lower serum carotenoid levels among marijuana users than among the non-current users, which may be due to the oxidative effect of cigarette smoking. When we examined serum carotenoid levels stratified by cigarette smoking, we found that among non-cigarette smokers, marijuana users had lower carotenoid levels than non-current marijuana users. Similarly, among cigarette smokers, marijuana users had lower carotenoid levels than non-current marijuana users (data not shown). These results suggest that marijuana use is associated with lower serum carotenoid levels independent of cigarette smoking. Sarafian et al. found marijuana smoke to be a source of cellular oxidative stress $^{13}$, which may in part explain the differences in serum carotenoids. The differences may also in part be due to the lower dietary carotenoid intake, higher alcohol intake, and lower frequency of fruit and vegetable consumption among the heavy users than among noncurrent users (Tables 3 and 4).

Using cross-sectional data limits our ability to assess cause-and-effect relationships. However, these data are very useful in estimating marijuana use and describing intake patterns among groups of individuals. The 24-hour recall does not reflect usual or individual intake and does not include supplemental intake. It does provide reasonable group estimates of dietary nutrient intake ${ }^{14}$. The FFQ does not provide quantitative nutrient information, but it does provide information on the usual consumption of specific foods or food groupings. Little is known about the cognitive impact of marijuana use on diet recall. We also do not have information on the amount of marijuana smoked and do not know the extent of underestimation of marijuana frequency. Despite these limitations, we consider that these data provide reasonable estimates of dietary intake by marijuana use.

In summary, marijuana users had higher intakes of energy and nutrients than non-marijuana users and did not appear to have a poor nutritional status using indicators of body mass index, serum nutrients, serum albumin, haematocrit and haemoglobin. At the same time, marijuana users had a higher consumption of sodium, lower fruit intake, lower serum carotenoid levels, higher alcohol intake, and higher rate of cigarette smoking. The longterm health effects of these lifestyle habits among marijuana users deserve careful consideration in future research.

\section{References}

1 Office of Applied Studies, Substance Abuse and Mental Health Services Administration. National Housebold Survey on Drug Abuse: Main Findings 1998. Rockville, MD: US Health and Human Services, March 2000.

2 National College Health Risk Behavior Survey, Unites States 1995. In: CDC Surveillance Summaries, November 14, 1997. MMWR 1997; 46(SS-6).

3 Watson SJ, Benson JA Jr, Joy JE. Marijuana and medicine: assessing the science base: a summary of the 1999 Institute of Medicine report. Arch. Gen. Psychiat. 2000; 57(6): 547-52.

4 Mohs ME, Watson RR, Leonard-Green T. Nutritional effects of marijuana, heroin, cocaine, and nicotine. J. Am. Diet. Assoc. 1990; 90(9): 1261-7.

5 Mendelson JH. Marijuana use: biologic and behavioral aspects. Postgrad. Med. 1976; 60(5): 111-5.

6 Hollister LE. Hunger and appetite after single doses of marijuana, alcohol, and dextroamphetamine. Clin. Pharmacol. Ther. 1971; 12(1): 44-9.

7 Foltin RW, Fischman MW, Byrne MF. Effects of smoked marijuana on food intake and body weight of humans living in a residential laboratory. Appetite 1988; 11(1): 1-14.

8 Zwillich CW, Doekel R, Hammill S, Weil JV. The effects of smoked marijuana on metabolism and respiratory control. Am. Rev. Respir. Dis. 1978; 118(5): 885-91.

9 National Center for Health Statistics. Plan and Operation of the Third National Health and Examination Survey, 19881994. Vital Health Statistics 1[32]. Hyattsville, MD: US Health and Human Services, Public Health Service, Centers for Disease Control and Prevention, National Center for Health Statistics, 1994.

10 National Center for Health Statistics. The Third National Health and Nutrition Examination Survey Reference Manuals and Reports. CD-ROM. Hyattsville, MD: US Health and Human Services, Public Health Service, Centers for Disease Control and Prevention, National Center for Health Statistics, 1996.

11 Allain CC, Poon LS, Chan CSG, Richmond W, Fu PC. Enzymatic determinations of total serum cholesterol. Clin. Chem. 1974; 20: 470-5.

12 Morabia A, Fabre J, Chee E, Zeger S, Orsat E, Robert A. Diet and opiate addiction: a quantitative assessment of the diet of non-institutionalized opiate addicts. Br. J. Addict. 1989; 84(2): 173-80.

13 Sarafian TA, Magallanes JAM, Shau H, Tashkin D, Roth MD. Oxidative stress produced by marijuana smoke: an adverse effect enhanced by cannabinoids. Am. J. Respir. Cell Mol. Biol. 1999; 20: 1286-93.

14 Karvetti RL, Knuts LR. Validity of the 24-hour dietary recall. $J$. Am. Diet. Assoc. 1987; 85: 1437-42. 